\title{
DE ANÔNIMO A BEST-SELLER: digressões sobre o sucesso do Projeto Araribá - História no PNLD de 2008

\author{
Jeferson Rodrigo da Silva*
}

\begin{abstract}
Resumo
Considerando o fato de a coleção Projeto Araribá: História ser uma das mais distribuídas pelo PNLD de 2008, as características que a tornaram uma obra singular e o contexto educacional do início do século XXI, este texto problematiza os aspectos relacionados à constituição, à divulgação e à escolha dessa obra que podem explicar tal sucesso. São apresentadas algumas características gerais como: a abrangência da coleção para diversas disciplinas, o objetivo de desenvolver a competência leitora, a autoria coletiva e o contexto da editora Moderna após a entrada do grupo espanhol Santillana. Com o intuito de ampliar a discussão, busca-se compreender, além do objetivo de desenvolver a competência leitora, a apresentação da coleção no PNLD de 2008, as estratégias agressivas de venda e a autoria coletiva como identidade da coleção. Conclui-se que o sucesso dessa coleção está vinculado a complexas relações entre as atuais demandas para um ensino de qualidade e os interesses comerciais, bem como entre a constituição de uma ferramenta que busca desenvolver a leitura proficiente e as políticas públicas que, de certo modo, legitimam os propósitos da coleção.
\end{abstract}

Palavras-chave: História e ensino. Livro didático. Projeto Araribá. PNLD. Leitura.

\section{FROM ANONYMOUS TO BEST-SELLER: digressions on the success of Project Araribá - História in the PNLD of 2008.}

\begin{abstract}
Considering the fact of the collection Projeto Araribá: História to be one of the most distributed by the PNLD of 2008, the characteristics that made it a unique work and the educational context of the XXI century, this text discusses the aspects related to the constitution, distribution and choice of this work that can explain your success. In this sense, some general characteristics are discussed as: the scope of the collection to various disciplines, the objective of developing the reading competence, the collective authorship and the context of Moderna publishing house after the entry of the Spanish group Santillana. In order to expand the discussion, we seek to understand, outside the purpose of developing the reading competence, the presentation of the collection in the PNLD of 2008, the aggressive sales strategies and the collective authorship as identity of the collection. It is concluded that the success of this collection harnesses to complex relationships between the current demands for the quality education and the commercial interests, as well between the creation of a tool that seeks to develop proficient reading and the public policies that, somehow, legitimate the purposes of the collection.
\end{abstract}

Keywords: History and teaching. Textbook. Projeto Araribá. PNLD. Reading.

\footnotetext{
* Mestre em História Social pela Universidade Estadual de Londrina. Professor da Rede Pública de Ensino do Estado do Paraná. E-mail: b_crowesbr@yahoo.com.br
} 


\section{Introdução}

No ano de 2007, os professores de escolas públicas, em todo o país, fizeram a escolha do livro didático a ser utilizado por mais um triênio. Os valores negociados pelo MEC ultrapassaram a casa dos quinhentos milhões de reais. A editora Moderna foi a maior fornecedora de livros didáticos daquele ano, com um volume pouco maior que cento e sessenta milhões de reais ${ }^{1}$.

Dentre as coleções da editora, interessa-nos uma em especial: a coleção Projeto Araribá - História. Algumas reportagens jornalísticas do período, como a que se encontra no jornal Folha de São Paulo do dia 30 de setembro de 2007, justificam o nosso interesse:

Coleção mais escolhida pelos professores, "Projeto Araribá - História", da editora Moderna, terá 5,7 milhões de exemplares distribuídos às escolas de $5^{\mathrm{a}}$ a $8^{\mathrm{a}}$ série em 2008. Deixará para trás os 2,5 milhões vendidos no Brasil pelos seis primeiros volumes de "Harry Potter" e o 1,5 milhão do "Código da Vinci". (PINHO; SELIGMAN, 2007)

Com o título compras do MEC fazem anônimo virar best-seller, a reportagem indicava que, entre as obras mais vendidas naquele momento, havia se destacado uma coleção estreante em seleções do PNLD, mas já figurando entre aquelas com maior número de escolhas. Essa evidência leva a uma questão fundamental: por que essa coleção foi a mais utilizada em escolas públicas entre os anos de 2008 e 2010 ?

Tivemos um primeiro contato com a coleção Projeto Araribá - História quando desenvolvemos uma pesquisa cujo objetivo era compreender as práticas de leitura do livro didático por professores e alunos em sala de aula na cidade de Cambé-PR ${ }^{2}$. Nela, os dois professores participantes utilizavam a referida coleção.

Durante o mestrado ${ }^{3}$ encontramos esta coleção novamente e, destes encontros e reencontros, alguns questionamentos a respeito de sua constituição e do trajeto percorrido até tornar-se uma das obras didáticas mais escolhidas pelas escolas públicas, fizeram-se inevitáveis. Para além de elogiar o seu sucesso ou criticar sua abordagem, buscamos

\footnotetext{
1 Estes números encontram-se na tabela de valores negociados para o PNLD 2008, disponível em: $<\mathrm{ftp}: / / \mathrm{ftp}$. fnde.gov.br/web/livro_didatico/planilha_pnld.pdf $>$.

${ }^{2}$ Esta pesquisa foi realizada, entre os anos de 2008 e 2009, no curso de especialização em História Social e Ensino de História da Universidade Estadual de Londrina, sob orientação da professora Dra . Ana Heloisa Molina.

${ }^{3}$ Nesta pesquisa, buscamos aprofundar a problemática desenvolvida anteriormente. O trabalho foi realizado, entre 2010 e 2011, no programa de pós-graduação em História Social (linha História e Ensino) da Universidade Estadual de Londrina. A dissertação final intitula-se Artes de fazer o ensino de História: professor, aluno e livro didático entre os saberes admitido e inventivo. A pesquisa também foi orientada pela professora $\operatorname{Dr}^{\mathrm{a}}$. Ana Heloisa Molina e financiada pela CAPES.
} 
compreendê-la como um documento histórico. Neste artigo, apresentaremos o recorte da análise realizada em nossa dissertação que remete à problematização do processo de construção, divulgação e seleção da referida coleção.

\section{Quatro características gerais do Projeto Araribá}

De início, apresentaremos quatro características gerais da coleção que a situam histórica e geograficamente nos contextos educacionais e mercadológicos existentes nos primeiros anos do século XXI. São elas, respectivamente: a abrangência para diversas disciplinas, o seu objetivo principal, a origem do nome e a autoria coletiva.

A coleção Projeto Araribá foi lançada pela editora Moderna, inicialmente, no ano de 2003. Esta coleção contém quatro volumes direcionados para os anos finais do ensino fundamental. De maneira peculiar, ela foi editada para as disciplinas de Língua Portuguesa, Matemática, Ciências, Geografia e História. A editora Moderna dispunha de um site no qual, de forma sintética, apresentava, aos consumidores em potencial, a relação entre as diversas disciplinas contempladas pela coleção e seus objetivos gerais:

O Projeto Araribá oferece às escolas um projeto para contribuir com a melhoria da qualidade do ensino. Um projeto com princípios claros, compartilhados pelos membros da comunidade educativa, que guiam as ações para atingir os melhores resultados. São três os princípios básicos do Araribá: Programas específicos em cada disciplina para desenvolver a competência leitora, programa de atividades, com propostas variadas e em um nível crescente de complexidade, organização clara. ${ }^{4}$ (JORNAL EDUCAR, 2008, p. 30, grifos nossos).

Um dos objetivos fundamentais desta coleção é, segundo os responsáveis, o desenvolvimento do que eles denominaram competência leitora, por meio de uma organização de conteúdos clara e sistematicamente projetada para desenvolver tal competência de maneira complexa, considerando os níveis crescentes de dificuldade para cada ano escolar e as especificidades de cada disciplina. Assim, concluímos que cada conjunto de livros desenvolve aspectos específicos desta competência leitora, possibilitando o entendimento de que ela será devidamente desenvolvida com a utilização de todos os livros em suas respectivas disciplinas. De antemão, destacamos o caráter pedagógico e

\footnotetext{
${ }^{4}$ Quando inserimos essa citação no trabalho, ela estava disponível no site da editora Moderna, porém, este site foi retirado do ar, sendo possível visualizar apenas as páginas da edição mais nova. No espaço de divulgação de livros do Jornal Educar, n. 56 de 2008, encontramos a mesma descrição, exceto pela primeira frase que encontrávamos no site da editora: "um projeto para desenvolver a competência leitora".
} 
mercadológico desta proposta que, de um lado, compartimenta e especializa um objetivo geral e, de outro, justifica a escolha de livros de uma mesma coleção para diferentes disciplinas.

Sobre a origem do nome, nas capas das reimpressões da primeira edição, constatamos que “Araribá é o nome de várias espécies de árvores de grande porte, nativas do Brasil”. De acordo com Maria Raquel Apolinário ${ }^{5}$, "Escolhemos esse nome porque queríamos uma palavra e um objeto identificados com as nossas raízes indígenas, além de a palavra produzir um efeito sonoro que nos agradava” (Entrevista, 19/12/2011). Nestas falas, destacamos a necessidade de fortalecer, de certa forma, a identidade nacional na escolha do nome. Essa informação será pertinente quando contemplarmos, posteriormente, o contexto de produção da obra.

A respeito da autoria, a coleção Projeto Araribá apresenta outra característica peculiar. Ao contrário de grande parte das coleções publicadas até hoje, em que um autor responde pelos originais ou, em certos casos, existe uma parceria de autores, as obras desta coleção têm um editor responsável pelo trabalho e uma equipe de profissionais que assina como elaboradores dos originais.

Por meio de um depoimento presente na tese de Munakata (1997), constatamos que este tipo de relação entre os autores e editores é um dos caminhos para que uma editora obtenha os originais de uma coleção didática:

Outra origem do original - origem do original é bom, né? - é quando a editora elabora internamente um projeto editorial, e com base nesse projeto ela tenta encontrar os autores que seriam capazes de executar o projeto. Sendo assim, a editora, às vezes, é obrigada até a contratar temporariamente o autor. Contratar entre aspas, quer dizer, adiantar dinheiro para que o autor execute esse trabalho. Isso é quando o projeto é feito pela editora e se vai atrás do autor com o projeto pronto. ${ }^{6}$ (MUNAKATA, 1997, p. 138).

Na tese de Cassiano encontramos uma entrevista anônima, atribuída a uma professora, na época, editora responsável da coleção Projeto Pitanguá para a disciplina de Língua Portuguesa, que contribui para a compreensão das relações entre a editora Moderna e os profissionais envolvidos na criação das coleções com projetos editoriais elaborados anteriormente:

\footnotetext{
${ }^{5}$ A editora responsável pela coleção Projeto Araribá - História, gentilmente, concedeu uma entrevista por email, respondendo algumas questões que formulamos com o intuito de compreender o processo de constituição da obra. Conseguimos um primeiro contato em agosto de 2011. Depois lhe enviamos um roteiro que recebemos com as respostas e a autorização para divulgação no dia 19 de dezembro de 2011.

${ }^{6} \mathrm{O}$ depoimento colhido por Munakata é de Lizânias de Souza de Lima, editor da FTD.
} 
No final de novembro de 2001, fui convidada pela editora Moderna para participar da produção de dois livros didáticos de Língua Portuguesa para a $3^{\mathrm{a}}$ e $4^{\mathrm{a}}$ série do ensino fundamental. Foi dito que os livros seriam produzidos a quatro mãos, processo chamado pela editora de obra coletiva com cessão exclusiva de direitos.

Houve uma conversa inicial para explicação de todo o processo. O modelo a ser seguido era um modelo espanhol de muita aceitação na Espanha e em países da América do Sul [...]. Coube a mim e à colega com quem produzi os livros: produção, elaboração, seleção e adaptação de textos (alguns em espanhol), atividades, respostas, orientações didáticas, bibliográficas, indicação de sites ao professor, seleção e sugestão de imagens. O envio de material ocorreu, em sua maior parte, via e-mail. Os pagamentos ocorreram dentro do prazo. Nosso nome, acompanhado de um breve currículo, aparece na $1^{\text {a }}$ contra capa dos quatro livros da coleção, junto com os demais autores, como Equipe de Elaboração. Internamente, não há citação de nosso nome como autoras de alguns textos. ${ }^{7}$ (CASSIANO, 2007, p. 176).

Evidentemente, não se trata da coleção analisada neste artigo. Entretanto, pelo fato delas pertencerem à mesma editora e terem sido construídas em épocas próximas, podemos afirmar que este testemunho indica procedimentos semelhantes àqueles realizados na construção do Projeto Araribá. Acreditamos que o próximo item será elucidativo a respeito disso.

\section{Itinerários de constituição do Projeto Araribá - História}

As características gerais abordadas até o momento referem-se às coleções de todas as disciplinas abarcadas pelo projeto. Daqui em diante, restringiremos as análises à coleção concebida para a disciplina História. Como indicando no item anterior, Projeto Araribá História foi produzido sob responsabilidade editorial de Maria Raquel Apolinário. Ela conta sua trajetória profissional, dentro da editora Moderna, da seguinte forma:

Entrei na Moderna em janeiro de 1996, depois de participar de um processo de seleção para vagas de preparador de textos. Virginia, a gerente do editorial de humanas na época, teve acesso ao meu currículo, me chamou para uma entrevista, fiz uma redação e outra entrevista com a área de RH e fui selecionada para a vaga no editorial. Trabalhei neste editorial até 2001, quando a Moderna foi comprada pelo grupo espanhol Santillana. Assim que a compra se concluiu, os espanhóis decidiram criar no editorial um núcleo de obras coletivas, que faria o primeiro projeto editorial do grupo no Brasil, o Projeto Pitanguá, para as séries iniciais, e eu fui convidada a assumir a disciplina de história nessa nova equipe. Fizemos o Pitanguá e, em 2002, iniciamos o trabalho com o Projeto Araribá. (APOLINÁRIO, 2011, grifos nossos).

\footnotetext{
${ }^{7}$ Depoimento de professora anônima concedida a Cassiano no dia 12 de novembro de 2003.
} 
Existem vários elementos relevantes, para a análise, nesta fala. Por enquanto, é pertinente ressaltarmos a existência de relações entre o Projeto Pitanguá e o Projeto Araribá e o fato de a entrevistada trabalhar na editora antes da concepção do projeto. Essas características demarcam o lugar de atuação da editora responsável e reforçam os argumentos do depoimento que tomamos de empréstimo da tese de Cassiano (2007).

Até o momento, foram lançadas três edições desta coleção com modificações significativas: a primeira em 2003, a segunda em 2007 e a terceira em 2010. Além destas, foram publicadas diversas reimpressões de cada edição com correções e ajustes. A edição que obteve sucesso no PNLD de 2008 tratava-se de uma reimpressão da primeira edição, feita em 2006. Visualmente, sua característica mais marcante é a capa na cor azul, uma vez que as edições anteriores tinham capa branca.

As mudanças de uma edição para outra estão fortemente ligadas à recepção que a coleção teve entre os professores, como podemos constatar no próprio site de divulgação da obra: “O novo Projeto Araribá foi atualizado a partir de entrevistas com professores, trazendo recursos pedagógicos atraentes para potencializar o processo de ensino-aprendizagem” (PROJETO ARARIBÁ, 2012). Outro aspecto importante diz respeito às significativas alterações feitas para a edição do PNLD de 2008. Com os direitos da obra sendo da própria editora, acreditamos que essas alterações fossem previsíveis e, provavelmente, até planejadas no início do projeto, uma vez que a sua constituição permite a entrada e saída de pessoas sem que a autoria seja prejudicada e com um mínimo de prejuízo à editora. Ao comentar o processo de constituição da equipe editorial, Maria Raquel Apolinário fornece indícios importantes sobre este aspecto:

As equipes que fizeram o Projeto Pitanguá e depois o Projeto Araribá foram selecionadas, em geral, dentro das próprias editorias de cada disciplina. Os diretores e gerentes que fizeram a seleção levaram em consideração a trajetória dos editores na empresa, os trabalhos feitos, o conhecimento técnico dessas pessoas e a habilidade que expressavam não apenas em editar textos, mas em criar conteúdos, elaborar atividades e inovar em propostas editoriais. Ao longo dos anos, vários editores do núcleo original, responsáveis por disciplina, saíram da empresa e foram substituídos por novos editores, em geral aproveitados das próprias editorias. Acredito que a área de história, hoje, seja a única em que o editor responsável é o mesmo desde que o Pitanguá nasceu como projeto, em 2001. (APOLINÁRIO, 2011)

Mesmo com a permanência da editora responsável, a variação de profissionais, ao longo da história desta coleção, representa uma parte das complexas relações editoriais que 
permitiram a constituição do Projeto Araribá - História à medida que as contribuições de diversos profissionais iam sendo acrescentadas.

Permanecendo nas diferenças significativas entre as primeiras impressões, direcionadas para as escolas particulares, e a edição formulada para o PNLD, percebemos que, em algumas impressões da primeira edição, a coleção apresentava-se com encadernação espiral e papel couché - com exceção da primeira impressão - enquanto a edição do PNLD apresentava-se como brochura impressa em papel offset. Acreditamos que esta evidência remeta diretamente aos custos do livro que, no caso da edição para o PNLD de 2008, era menor do que nas impressões anteriores ${ }^{8}$. A segunda e a terceira edições não são em espiral e possuem tamanho maior; modificação, possivelmente, decorrente de uma coleção consolidada no mercado. Notamos que a alteração no tamanho também se mostra no layout dessas edições mais recentes que apresentam elementos gráficos maiores e uma quantidade significativa de atrativos visuais.

Para Bittencourt (2008), Munakata (1997), Gatti Júnior (2004), Choppin (2007) e diversos outros pesquisadores, o livro didático deve ser pensado como mercadoria e, neste caso, entendemos que o principal objetivo dessas alterações era conquistar mais consumidores. Se considerarmos apenas as especificidades da edição para o PNLD de 2008, as mudanças têm estreita relação com o objetivo principal da editora naquele momento, ou seja, conseguir a aprovação no PNLD e ser adotada pelas escolas públicas.

Falando ainda sobre o barateamento da produção de livros didáticos, percebemos que os cortes de gastos para impressão da obra foram uma preocupação desde o início da coleção que, até sua impressão de 2006, foi feita na China.

Nas falas de Maria Raquel Apolinário, apresentadas anteriormente, verificamos outro aspecto importante sobre a constituição da coleção Projeto Araribá - História. Trata-se das medidas políticas de abertura para o capital estrangeiro durante o governo de Fernando Henrique Cardoso (1995-2002) e dos rumos tomados pela editora Moderna no início do século XXI.

De acordo com Cassiano (2007), as atitudes tomadas por este governo possibilitaram a entrada de grandes grupos espanhóis no país que adquiriram diversas empresas, inclusive públicas, acrescentando-se a elas e transformando a Espanha no maior investidor em terras nacionais, entre os anos de 1998 e 2000, juntamente com os Estados Unidos. Neste contexto, várias editoras brasileiras, fundadas por grupos familiares, foram compradas por empresas

\footnotetext{
${ }^{8}$ Para as coleções distribuídas no PNLD de 2008, a média de custo por exemplar comprado foi R\$ 5,06 .
} 
estrangeiras. Entre elas está a editora Moderna, adquirida em 2001 pela Santillana, braço editorial do grupo espanhol Prisa (CASSIANO, 2007; SILVA, 2009).

Outro aspecto importante, nessa discussão, é a participação voluntária do Brasil no PISA $^{9}$ de 2000, quando obteve, nos resultados gerais, a última posição entre trinta e dois países participantes de uma pesquisa que avaliou, entre outros, o letramento em leitura dos estudantes. Este resultado tornou evidente, para os nossos governantes, que os alunos não sabiam ler - no sentido proposto pelo letramento -, informação exaustivamente explorada pelo grupo Santillana, desde sua entrada no Brasil, por meio de encontros denominados Seminário de Outono que “[...] objetivaram debater o Programa Internacional de Avaliação de Estudantes (PISA), assim como analisar o desempenho dos alunos brasileiros nessa avaliação internacional, em que o Brasil participou de forma voluntária, [...].” (CASSIANO, 2007, p. 186).

Os debates legitimaram a participação do Brasil no PISA porque discutiram os péssimos resultados dos alunos, porém, não trataram das possíveis adequações daquela avaliação à realidade em que vivemos (CASSIANO, 2007). O grupo Santillana, por meio da editora Moderna, divulgou os resultados globais do PISA, no formato impresso, com o livro Conhecimentos e atitudes para a vida - resultados do PISA 2000, publicado no ano de 2003 (SILVA, 2009).

Nas referências do Guia e recursos didáticos ${ }^{10}$ da coleção Projeto Araribá - História, nós encontramos a publicação do INEP, intitulada PISA 2000 - Relatório Nacional, na qual constatamos a presença de elementos que fundamentam a constituição da obra:

Sensibilizar os professores das diversas áreas para a noção de que o desenvolvimento das habilidades de leitura é um objetivo a ser atingido pela escola nas diversas áreas curriculares e de que a especificidade de cada área curricular oferece oportunidades singulares para o aprimoramento de diferentes habilidades de leitura é um desafio que o Pisa contribui para atualizar. (BRASIL, 2001b, p. 72-73).

Desafio este que a coleção buscava desenvolver nas diversas disciplinas, incluindo a História. Mesmo tendo grande contribuição, o PISA não foi o único instrumento de avaliação da qualidade da educação a influenciar o surgimento do Projeto Araribá - História. No início

\footnotetext{
${ }^{9}$ O Programme for International Student Assessment, ou, como é conhecido no Brasil, o Programa Internacional de Avaliação de Estudantes “[...] é um esforço de colaboração entre os países membros da OCDE para medir até que ponto jovens de 15 anos, [...] estão preparados para enfrentar os desafios de conhecimento da sociedade de hoje” (OCDE, 2003, p. 14). Esta avaliação é focada no letramento em leitura, letramento em matemática e letramento em ciências, sendo que, a cada três anos, um desses campos é priorizado.

${ }^{10}$ Em outras coleções didáticas, esta publicação equivale ao manual do professor.
} 
do século XXI, houve uma forte tendência, por parte de algumas instituições públicas e privadas, em avaliar e discutir a formação leitora dos alunos que, possivelmente, foram aproveitados pelo grupo Santillana e pela editora Moderna.

Entre as iniciativas, destacamos o Sistema Nacional de Avaliação da Educação Básica - o SAEB ${ }^{11}$ - promovido pelo INEP. Sendo uma pesquisa realizada desde 1995, ela tem por objetivo “[...] subsidiar e induzir políticas orientadas para a melhoria da qualidade da educação brasileira.” (BRASIL, 2001a, p.10).

Na apresentação do instrumento de pesquisa, constatamos sua pertinência para a análise da obra didática porque, na edição de 2001, os testes eram direcionados para as disciplinas de Língua Portuguesa e Matemática com ênfase na leitura/compreensão de textos.

A pesquisa é mencionada, no Guia e recursos didáticos da coleção Projeto Araribá História, por meio das Matrizes curriculares de referência, publicadas em 1999, o que evidencia dois aspectos: primeiro, que os problemas apontados nos relatórios, em relação às habilidades necessárias para o desenvolvimento da leitura, serviram de fundamento para o objetivo principal da obra; segundo, que a constituição do conceito competência leitora pela coleção Projeto Araribá - História está, em parte, atrelada a este instrumento de pesquisa que busca avaliar as competências necessárias para o desenvolvimento da leitura proficiente:

No caso específico de Língua Portuguesa, procurou-se, por meio de testes voltados para a compreensão de textos, observar quais as competências que já foram construídas pelos alunos e quais as que estão em processo de construção, nas diversas séries avaliadas. (BRASIL, 2001a, p. 102).

A segunda pesquisa que merece atenção intitula-se Retratos da leitura no Brasil, realizada, pela primeira vez, entre os anos de 2000 e $2001^{12}$ e, posteriormente, no ano de 2007. Ao contrário do SAEB, realizado pelo governo, esta pesquisa foi encomendada por instituições particulares. Em sua primeira edição, ela foi promovida pela CBL, SNEL e Abrelivros. Seu principal objetivo era:

\footnotetext{
${ }^{11}$ De acordo com o site do INEP, o SAEB tem por objetivo geral realizar diagnósticos do sistema educacional brasileiro e de fatores que possam interferir no desempenho dos alunos, fornecendo um indicativo sobre a qualidade do ensino ofertado. Mesmo tendo se iniciado em 1990, apenas em 1995 ele se tornou uma avaliação de questões com itens, sendo aplicada nos anos finais de cada ciclo, a saber: $4^{\mathrm{a}}$ série $\left(5^{\mathrm{o}}\right.$ ano $), 8^{\mathrm{a}}$ série $\left(9^{\mathrm{o}}\right.$ ano $)$ e $3^{\mathrm{a}}$ ano do ensino médio. A partir da avaliação de 2001, a que mais nos interessa, o SAEB privilegiou as disciplinas de Língua Portuguesa e Matemática. A amostragem dessa pesquisa foi de 287.210 alunos.

${ }^{12}$ A pesquisa foi aplicada a jovens com, no mínimo, 14 anos de idade e 3 anos de escolaridade. Foram realizadas 5.200 entrevistas em quarenta e quatro municípios de dezenove estados brasileiros. Esta pesquisa consiste de entrevista domiciliar.
} 
[...] identificar a penetração da leitura de livros no país e o acesso a eles. Além disso, também buscava: a) Levantar o perfil do leitor de livros; b) Coletar as preferências do leitor brasileiro; c) Identificar as barreiras para o crescimento da leitura de livros; d) Levantar o perfil do comprador de livros. (INSTITUTO PRÓ-LIVRO, 2008, p. 7).

Na apresentação da segunda edição desta pesquisa, publicada em 2008, percebemos a recorrente preocupação com a formação dos jovens leitores no país:

Constitui uma resposta institucional à preocupação de especialistas de diferentes segmentos - das áreas de educação, cultura e produção e distribuição do livro - pelos níveis de leitura da população em geral e, em particular, dos jovens, significativamente inferiores à média dos países industrializados e em desenvolvimento. (INSTITUTO PRÓ-LIVRO, 2008, p.4).

Considerando que, da primeira para a segunda edição, mudanças significativas, referentes às iniciativas de incentivo à leitura, ocorreram no país, reafirmamos que o documento constitui-se em uma forma de divulgação e legitimação da situação constatada no PISA e no SAEB (SILVA, 2009): não éramos um país de leitores proficientes e isso precisava mudar.

Além das pesquisas mencionadas até o momento, existe um documento que também menciona a necessidade de desenvolvimento da capacidade de leitura. Trata-se do texto Para formar um país de leitores: contribuições para a política do livro escolar no Brasil, escrito em 2002 por profissionais das instituições ligadas à Abrale e Abrelivros e endereçada ao governo de Luiz Inácio Lula da Silva (2003-2010) que assumira a presidência naquele momento. A introdução do documento é fundamental para compreendermos sua pertinência na constituição da coleção didática analisada neste artigo. Segundo os autores, o texto:

[...] Exprime [...] a visão de autores, empresários do livro e profissionais de edição que, antes de expressar apenas interesses, manifestam-se, sobretudo, como cidadãos brasileiros que podem contribuir para a melhoria da educação e para a formulação de uma adequada política para o livro no Brasil. (ABRALE; ABRELIVROS, 2002, p. 3).

Dentre os motivos que justificaram a produção daquele texto, os autores enfatizaram a importância que a leitura tem na formação de cidadãos críticos e criativos, reconhecendo a escola como agente fundamental na formação de leitores regulares e conscientes; atribuíram ao Estado a obrigação de formar professores capazes de articular estratégias que contribuíssem para a formação dos leitores, além de colocar para os novos governantes o 
dever de fornecer livros de gêneros variados para as bibliotecas; assinalaram a necessidade de aprimoramento do processo de distribuição de livros às escolas e avaliaram criticamente o PNLD, desde 1995 até aquele momento, apontando aspectos positivos e reivindicando mudanças.

Mesmo reconhecendo que este documento mostra-se, principalmente, como uma reivindicação por mudanças na estrutura do PNLD, ele dialoga diretamente com o PISA, com o SAEB e com os Retratos da leitura no Brasil ao ressaltar o contexto preocupante no qual a leitura proficiente é deficitária no Brasil, atribuindo à escola o papel principal de reverter essa situação, uma vez que as famílias não têm, segundo alguns desses documentos, participação significativa no desenvolvimento da compreensão leitora de seus filhos. Os professores receberam, de instrumentos legitimadores dos problemas na formação leitora dos jovens brasileiros, a missão de transformar os alunos em leitores críticos e criativos.

A coleção Projeto Araribá - História surge neste contexto, em que a situação precisava mudar, como uma possibilidade de resolver o problema (SILVA, 2009). A proposta do projeto consiste no desenvolvimento de competências essenciais em cada uma das disciplinas contempladas pela coleção, o que permite ao livro de História definir como meta o desenvolvimento da leitura proficiente nos alunos. Os objetivos da coleção sintetizados na capa da primeira edição, impressa em 2003, fornecem alguns elementos importantes para a compreensão desse engajamento:

\footnotetext{
Características da área

Ajuda a formar uma idéia clara dos acontecimentos. Permite entender a História em profundidade.

Desenvolve o juízo crítico e o respeito à diversidade.

Características do Projeto

Programas para desenvolver a competência leitora.

Uma organização clara, que facilita a aprendizagem.

Atividades para alcançar todos os objetivos.

(PROJETO ARARIBÁ, 2003)
}

Percebemos que, além da ênfase nessa competência leitora, a organização clara e o desenvolvimento de juízo crítico são aspectos diretamente ligados à preocupação de desenvolver as habilidades de leitura.

Para concluirmos a análise dos aspectos relacionados ao contexto de criação, lembramos que a coleção Projeto Araribá insere-se em um conjunto de projetos mais abrangente, no qual estão envolvidos outros países além do Brasil. Para citarmos um exemplo, na Espanha, o grupo Santillana lançou, na mesma época em que a coleção Projeto Araribá foi 
publicada no Brasil, uma coleção denominada Proyecto los caminos del saber que possui livros para diversas disciplinas, inclusive História e Geografia, direcionados para a ESO (Educación Secundaria Obligatoria), com algumas semelhanças à coleção analisada nesta pesquisa. Dentre as características gerais, constatamos que ela também é de autoria coletiva e possui um editor responsável - no caso, Enrique Juan Redal - acompanhado de sua equipe. A obra prioriza o aprendizado de competências, a formação de valores morais e o desenvolvimento da compreensão leitora, objetivos semelhantes aos que encontramos na coleção analisada neste artigo.

Quando abordamos a justificativa para a escolha do nome, verificamos, pelas falas de Maria Raquel Apolinário, a importância de dar ao projeto uma identidade nacional. Possivelmente, esta é, dentre todas as particularidades da obra, aquela que mostra, de maneira categórica, que o projeto não foi direcionado unicamente para o Brasil.

Outro indicativo da proximidade está nas atividades realizadas pelo grupo Santillana com profissionais da editora Moderna. Antes da constituição do Projeto Araribá, os editores de obras coletivas passaram vários meses em São Paulo se reunindo com Jaime Mascaró sociólogo, pedagogo e editor do grupo editorial Santillana. Sobre essa experiência, Maria Raquel Apolinário ressalta que:

[...] foi a melhor experiência que vivi na Moderna nesses 16 anos de empresa. Aprendemos com ele a planejar com cuidado cada página que escrevíamos, a adequação das palavras, das atividades, a melhor forma de comunicar os conteúdos. Mas o melhor da experiência com o Jaime foi a possibilidade que tivemos, ou conquistamos, de conciliar o modelo que ele nos trazia, baseado na preocupação com a compreensão leitora, com as características dos livros, dos alunos, dos professores e da realidade do Brasil. Por isso, o Projeto Araribá estabelece muitos diálogos com as coleções de outras casas do grupo, mas a identidade maior é com a nossa cultura, com a nossa afetividade, com a nossa alegria e os nossos valores. Os livros refletem, além de pesquisas historiográficas feitas também em universidades brasileiras, a diversidade cultural, as questões e as contradições sociais do nosso país. (APOLINÁRIO, 2011)

Portanto, entendemos que a coleção analisada neste artigo tem sua constituição atrelada a um duplo movimento entre o modelo utilizado pelo grupo editorial Santillana intermediado pela presença de Jaime Mascaró - e as transformações e demandas nacionais que se tornaram mais evidentes ao final do século XX e início do XXI no Brasil. 


\section{Dimensão mercadológica ou como se tornar best-seller}

Por que esta coleção tornou-se a mais escolhida no PNLD de 2008? Iniciamos este item com mais uma fala de Maria Raquel Apolinário que destaca dois fatores principais para este sucesso:

O primeiro é pedagógico-editorial, ou seja, a própria natureza do projeto. Uma obra organizada, voltada à compreensão. Os textos são mais curtos, a linguagem é objetiva, as páginas são organizadas, textual e visualmente. O objetivo da obra não é formar historiadores, mas alunos que gostem e compreendam os conteúdos de história, que saibam estabelecer variadas relações, elaborar hipóteses, sistematizar informações, formular opiniões e conclusões, além de contribuir para construir cidadãos críticos, tolerantes, atuantes e solidários. Fora o fato de ser uma obra que ajuda os alunos a aprenderem história, ela tem uma seção em particular que para mim foi a grande novidade do Araribá em relação aos concorrentes: as monografias Em foco. Elas abordam temas como futebol, trabalho infantil, a história do milho, direitos humanos, o cangaço e muitas outras temáticas que trazem a história para o presente e o cotidiano do aluno.

O segundo fator é a competência da equipe de divulgação da Editora Moderna, que, respeitando as regras estabelecidas para a campanha de divulgação, soube promover eventos para comunicar a mensagem das nossas obras e apresentar adequadamente o aporte do Projeto Araribá para o ensino da história no ensino fundamental do Brasil. (APOLINÁRIO, 2011).

O período entre a criação e a seleção no PNLD agrega elementos importantes para o entendimento do grande número de vendas desta coleção. As falas de Maria Raquel Apolinário fornecem alguns indicativos que discutiremos ao longo deste item.

Silva (2009) acredita que um dos principais motivos para esse sucesso consiste na proposta de desenvolver a competência leitora, constatação que o autor aproxima ao dever, quase "impositivo", de os professores exercitarem a leitura nas aulas de outras disciplinas diferentes de Língua Portuguesa. Por meio das falas de Maria Raquel Apolinário citadas anteriormente, verificamos que esta perspectiva faz sentido:

[...] entendemos o livro didático não apenas como fruto das imposições de determinados grupos, mas também como convergência de diversos interesses, inclusive das necessidades reais de professores e alunos que neste momento demandam a didatização de proposições para o desenvolvimento da leitura. (SILVA, 2009, p. 82-83).

Portanto, o Projeto Araribá - História tornou-se fundamental no preenchimento da demanda pelo desenvolvimento de uma leitura proficiente pelos alunos. 
Centeno (2010) coloca outro elemento fundamental para a compreensão do sucesso de vendas da coleção. Ao afirmar que o Projeto Araribá - História foi escolhido por escolas de Campo Grande-MS, ela enfatiza que esta obra destacou-se não somente entre os professores daquele município, mas também entre os pareceristas do PNLD, por conta de sua ótima avaliação naquele ano.

Verificando o Guia de livros didáticos 2008: História ${ }^{13}$, encontramos indícios que vão ao encontro dessa afirmação. Naquela avaliação, foram definidos dez critérios cujos conceitos atribuídos poderiam ser Suficiente, Bom e Ótimo, conforme as avaliações feitas; o conceito Não foi usado quando determinado critério estava completamente ausente. Projeto Araribá História recebeu oito conceitos Ótimo e dois conceitos Suficiente, visivelmente diferenciados por cores (BRASIL, 2007, p. 17).

Cassiano (2007) ressalta que, até 2002, as avaliações do PNLD utilizavam critérios classificatórios para apresentar as obras nos guias, levando aquelas, cuja avaliação não fosse boa, a se tornarem mal vistas entre os professores. A partir de 2005, esses critérios foram retirados das avaliações. Ao invés da distinção por estrelas, utilizada anteriormente, o PNLD de 2005 listou os livros aprovados em ordem alfabética (MIRANDA; LUCA, 2004).

Se problematizarmos esta situação, considerando o quadro síntese do PNLD de 2008 (BRASIL, 2007, p. 17), percebemos que a distribuição de conceitos por cores, de certa forma, tornava implícita a existência de uma classificação das obras na qual a visualização dos livros mais bem conceituados era fácil, pois, as coleções com maior quantidade de conceitos Ótimo estavam, casualmente ou não, agrupadas.

Uma evidência de que esse aspecto foi explorado comercialmente aparecia no site de divulgação de outra coleção também avaliada positivamente no PNLD de 2008: a História em projetos da editora Ática. Neste sentido, encontramos, em alguns sites de venda de livros, a seguinte afirmação: “APROVADA pelo MEC no PNLD 2008 com Ótimo em todos os quesitos. A coleção mais bem avaliada de todo o programa. Uma coleção que transforma o estudo de História em uma fascinante viagem pelo espaço e pelo tempo” (LIVROFACIL, 2012).

Considerando essas evidências, faz sentido dizermos que o grande número de vendas do Projeto Araribá - História deveu-se à sua avaliação, mas, se observarmos com atenção, não seria lógico que História em Projetos, a coleção “mais bem avaliada pelo programa”, tivesse liderado o número de vendas ao final daquela seleção do PNLD? Por que esta coleção

\footnotetext{
${ }^{13}$ O Guia de Livros Didáticos trata-se de uma produção bibliográfica de caráter informativo, produzido pelo MEC, que relaciona todos os livros avaliados e aprovados pelo PNLD.
} 
não se sobressaiu ao Projeto Araribá em número de vendas? Essas questões obrigam-nos a relativizar este fator como determinante para a escolha da coleção didática analisada que, seguramente, pode ter suas vendas justificadas por essa avaliação, mas existem alguns aspectos que não podem ser descartados, a saber: o fato de uma parcela dos professores não ter o hábito de utilizar o guia como instrumento principal na escolha de livros didáticos (MUNAKATA, 2007; FREITAS et al, 2007; TIMBÓ, 2009; COELHO, 2009); o descompasso percebido, em determinados momentos, entre os livros considerados bons e as escolhas dos professores (BATISTA, 2001; GATTI JÚNIOR, 2004) e; a preferência por coleções com linguagem simplificada (MACHADO, 1996; FREITAS et al, 2007).

Um aspecto fundamental da análise mercadológica de livros didáticos diz respeito às possíveis estratégias da editora a fim de tornar uma obra atraente para os seus compradores, que neste caso são os professores das escolas públicas. Entre as possíveis estratégias, estão: o oferecimento de cursos, a distribuição de materiais anexos acompanhando as obras e a apresentação de determinadas coleções como produtos que seguem as últimas inovações pedagógicas e/ou as propostas curriculares atuais (BITTENCOURT, 2005, p. 311-312).

Na disputa pelo mercado de livros didáticos, Miranda e Luca (2004) atestam que editoras mais bem estruturadas têm larga vantagem sobre editoras menores por realizarem estratégias de venda mais agressivas. Esta afirmação torna-se relevante para esta análise porque, como mencionamos anteriormente, no início do século XXI, a editora Moderna tornou-se propriedade do grupo Santillana e, consequentemente, consolidou-se como uma grande editora naquele contexto histórico. Além disso, não podemos esquecer que Maria Raquel Apolinário aponta as estratégias de venda da editora Moderna como um fator importante para o sucesso da coleção.

Falando da produção editorial em meados da década de 1990, Gatti Júnior mostra que as estratégias de venda agressivas estiveram atreladas ao início do processo de avaliação do PNLD:

[...] a velocidade passou a ser uma das premissas da produção didática de então. Velocidade de produção e distribuição. Velocidade de atualização e de criação de novas coleções, com emprego de estratégias de vendas extremamente agressivas e caras. (GATTI JÚNIOR, 2004, p. 45).

A compra de editoras nacionais por empresas estrangeiras, principalmente espanholas e estadunidenses, marca uma nova forma de aproximação entre editoras e escolas, 
possivelmente, em relação à sua operacionalização, mas seguramente em relação à intensidade dessas estratégias:

[...] o aumento da concentração do mercado editorial, agora composto por poucos e grandes grupos editoriais, sendo alguns oriundos de potentes grupos midiáticos (a espanhola Santillana e o Grupo Abril), alteram sobremaneira as estratégias destas editoras em direção às escolas. (CASSIANO, 2007, p. 77).

No processo de escolha das coleções didáticas do PNLD de 2008, a repercussão dessa aproximação agressiva das editoras mostrava-se, inclusive, em reportagens jornalísticas como a que foi publicada na Folha Online do dia 30 de setembro de 2007:

Para conseguir a maior fatia de um mercado com essas proporções, algumas editoras utilizavam práticas que tiveram de ser disciplinadas por um "código de conduta" editado pelo MEC, por meio de portaria, em abril deste ano. Havia chegado à pasta denúncias de professores que recebiam brindes das empresas, de "representantes comerciais" que obtinham a senha usada por diretores de escola para selecionar o material e até de editora que imitava graficamente o catálogo enviado pelo MEC com resenhas de todos os livros disponíveis, mas eliminando as obras das concorrentes. A pasta, entretanto, não divulga os nomes das empresas.

Mesmo assim, as editoras continuam indo às escolas para divulgar seus produtos. É o caso, por exemplo, da Moderna, que em seu site oferece às escolas a visita de um consultor da empresa. A prática não é vetada pela portaria do MEC. (PINHO; SELIGMAN, 2007).

O “código de conduta”, editado pelo MEC e mencionado na reportagem, corresponde à portaria normativa $n^{\circ} 7$, publicada em 05 de abril de $2007^{14}$. Em sua tese, Timbó (2009) apresenta alguns depoimentos que indicam as tensões existentes entre esta portaria normativa e as estratégias das editoras:

[...] não há mais aquele corpo a corpo que existia dentro do espaço escolar, durante o estudo dos professores e até interferindo na escolha. [...] por mais que eles saibam e nós reforçamos que não podem ir até a escola fazer propaganda ou pressionar, eles acabam descobrindo onde é a casa dos professores ou mesmo do diretor, ou ficam lá debaixo do pé de juazeiro a distância só esperando um professor passar e muitas vezes chegam a abordar com o oferecimento de uma coleção de brinde e tentam saber quais foram as coleções escolhidas na pré-escolha ${ }^{15}$. (TIMBÓ, 2009, p. 109).

\footnotetext{
${ }^{14}$ Este documento definiu as normas de conduta do MEC, do FNDE, das editoras envolvidas com o PNLD, das secretarias de educação e das escolas para evitar abusos e favorecimentos ilícitos durante o processo de escolha de livros didáticos.

${ }^{15}$ Trecho de entrevista concedida por uma técnica do SMED no município de Quixadá-CE.
} 
Não podemos atribuir essas estratégias de venda à editora Moderna, porém, a possibilidade de ter acontecido algo semelhante não pode ser descartada, pois, com uma boa propaganda, é possível transformar uma coleção em best-seller.

Considerando as palavras de Sérgio Quadros - diretor executivo da editora Moderna em reportagem concedida para o Jornal O Estado de São Paulo, no dia 04 de outubro de 2007, onde diz que "Nossos livros são fáceis de serem trabalhados na sala de aula e fizemos um trabalho forte de marketing, de aproximação com os professores” (CAFARDO, 2007, grifo nosso); uma reportagem publicada no jornal Valor Econômico do dia 27 de maio de 2009, na qual se afirma que "O projeto mais agressivo da Santillana tem sido feito junto à Moderna. A produção de livros da editora para as escolas particulares saltou de 2,1 milhões em 2001 para 6,5 milhões de exemplares, entre livros didáticos e paradidáticos e apostilas em 2009” (KOIKE, 2009), ou mesmo as falas de Maria Raquel Apolinário anteriormente citadas, torna-se impossível desconsiderarmos as estratégias de venda como viabilizadoras do sucesso da obra.

Um exemplo de como a editora divulgou suas coleções são os Congressos Internacionais de Educação promovidos pela Fundação Santillana, em parceria com a Moderna, e realizado sete vezes até o presente momento.

Segundo Cassiano (2007), estes eventos tiveram ampla divulgação nas escolas públicas e privadas por meio de materiais diversos, além de terem sido divulgados em sites próprios, vinculados à editora Moderna. Ela ainda enfatiza que o público alvo desses eventos eram diretores, coordenadores, professores, acadêmicos e autoridades, sendo que não havia nenhum custo para a inscrição. “[...] em algumas edições do evento, houve distribuição de livros da Editora Moderna para os professores, além da promoção da Editora ao longo do evento, como patrocinadora do Congresso” (CASSIANO, 2007, p. 189).

Considerando essa descrição e as falas de Maria Raquel Apolinário apresentadas no início deste item, compreendemos a importância desses congressos como meio de aproximação entre a editora Moderna e os profissionais da educação - compradores em potencial de seus livros.

Historicamente, a realização de eventos aproximando editoras, autores e professores já era, na década de 1990, utilizada como forma de promover as publicações de diversas editoras. Pela carência de cursos de formação continuada promovidos pelo Estado, tais eventos acabavam preenchendo esse papel. Neste sentido, Munakata (1997, p. 124) ressalta que “[...] a Moderna promove os Encontros de Professores e Autores da Editora Moderna (EPAEM), em que autores ministram palestras sobre assuntos de sua especialidade”. Os 
Congressos Internacionais de Educação não foram, portanto, nem uma novidade e nem uma estratégia exclusiva da editora Moderna, mas tiveram grande importância neste processo.

Entre as edições do evento, destacamos duas: a terceira, realizada no ano de 2005, em Belo Horizonte-MG, cujo tema foi Ler sem limites ${ }^{16}$ e a quarta, realizada em São Paulo-SP e Salvador-BA, no ano de 2006, cujo tema foi Tempo, leitores e leituras ${ }^{17}$. Além de terem ocorrido em anos anteriores à escolha do PNLD de 2008, esses eventos priorizaram a leitura como um problema a ser debatido.

Estas iniciativas demonstram a preocupação com a formação de leitores críticos e criativos, enfatizada no fim da década de 1990, e reforçam, às vésperas do PNLD em que a coleção Projeto Araribá - História surge pela primeira vez como opção de escolha, a necessidade de nós, enquanto profissionais da educação, refletirmos a respeito da formação de uma leitura proficiente em todas as disciplinas. Quando há, efetivamente, a escolha do livro didático para o triênio seguinte, a pertinência da coleção analisada neste artigo, como ferramenta fundamental para a resolução de um problema exaustivamente abordado, tornou-se uma determinação positiva.

Esta determinação fez parte da justificativa de Silva (2009), para a análise da coleção Projeto Araribá - História, no momento em que ele constata a predominância desta obra entre os professores de Belo Horizonte-MG:

Neste quadro, constatou-se que os professores fizeram opção por livros que se apresentassem como capazes de favorecer a aprendizagem da História, exercitando o aprendizado da leitura de textos contínuos e descontínuos e, até mesmo, da escrita de pequenos textos. A indústria cultural, por sua vez, atenta a realidades como esta, parece fazer a adequação de seus produtos para atender às demandas do mercado. (SILVA, 2009, p. 81-82).

Considerando que a terceira edição do evento foi realizada em Belo Horizonte-MG, cidade onde o autor realizou sua pesquisa, nós levantamos a seguinte questão: até que ponto essa demanda foi legitimada pela realização do congresso, uma vez que é grande a chance dos professores entrevistados em sua pesquisa terem participado dele? E mais, como foi a repercussão desses congressos, entre os professores de Minas Gerais e de outros estados, pela disseminação das ideias apresentadas ou pela visita de representantes da editora nas escolas?

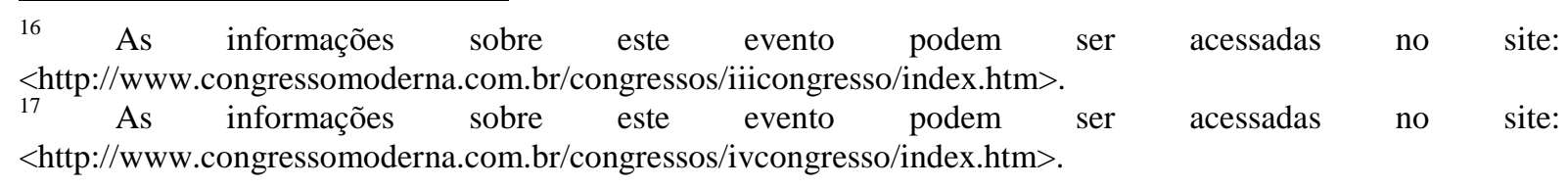


É importante lembrar que Minas Gerais, São Paulo e Bahia estão entre os estados com maior número de escolas de educação básica ${ }^{18}$.

Mesmo com estes indícios, não podemos atribuir, de forma determinante, o sucesso da coleção didática aos eventos promovidos pela editora Moderna e pelo grupo Santillana, uma vez que as discussões sobre formação leitora não foram elaboradas por estas empresas. Há uma complexa rede que compreende a demanda pelo desenvolvimento da leitura proficiente, as avaliações do PNLD e as estratégias agressivas de venda. Mesmo assim, é evidente que a exploração comercial de tal demanda, e o surgimento de uma ferramenta capaz de ajudar nesse problema, colocaram a editora em uma posição privilegiada, a ponto de justificar, parcialmente, o fato de Projeto Araribá - História ter sido a coleção mais escolhida no PNLD de 2008. Com as respostas de Maria Raquel Apolinário, percebemos que a editora tinha certa consciência dessa demanda por conta de pesquisas realizadas internamente:

A outra referência importante foi o diagnóstico que fizemos por meio de pesquisas com professores de escolas públicas e privadas de todo o Brasil. Nessas pesquisas, ficou claro que um dos maiores problemas que os professores reconheciam no processo de ensino-aprendizagem era a dificuldade de os alunos compreenderem os textos que liam. Mesmo em Matemática, os professores diziam que grande parte dos alunos não conseguia resolver problemas porque não compreendia o enunciado, o problema que era apresentado. Eles sabiam fazer contas, mas não conseguiam interpretar o problema e fazer as operações adequadas. (APOLINÁRIO, 2011).

Este fato mostra que devemos considerar as estratégias agressivas de vendas não como uma manobra arquitetada, engenhosamente, por profissionais dedicados a influenciar a opinião dos educadores, mas como um complexo jogo de tensões em que a constituição de uma determinação positiva concentra a busca pela qualidade na formação de nossos jovens e, ao mesmo tempo, lucros maiores.

Existem outras duas características relevantes para a análise que apresentamos neste artigo. De acordo com uma reportagem disponibilizada no site da AbreLivros, “[...] o livro tem linguagem menos coloquial que o anterior [referindo-se à coleção Nova História Crítica] e foi elaborado por um grupo de autores” (CAFARDO, 2007a). Logo abaixo, nesta mesma reportagem, essa informação é reforçada novamente: “História Projeto Araribá é uma coleção recente, de 2006, que tem uma concepção diferente, em que não apenas um único autor é responsável pelo conteúdo”.

\footnotetext{
${ }^{18}$ De acordo com o INEP, em 2009, o estado de São Paulo tinha 26.694 escolas; Bahia, 21.492 e Minas Gerais, 17.734 .
} 
Podemos supor que essas características da coleção tornaram-se atrativas para os consumidores se entendermos que uma autoria coletiva signifique múltiplas visões e abordagens acerca dos conteúdos, da concepção historiográfica e do método de ensino, mas ainda é possível problematizarmos essa informação. Para Centeno:

O Projeto Araribá História não faz indicação clara de autoria. [...] No verso da folha de rosto, dentre inúmeras informações, apresenta uma lista diminuta sob o título Elaboração de Originais, onde relaciona cinco nomes que, à exceção de um, são apontados como editores (as). Três deles são professores, quatro possuem apenas graduação e um é mestrando. Das observações apontadas, deduzimos preliminarmente: 1) a falta de interesse por parte da editora em divulgar os nomes dos autores; 2) os profissionais elencados, em sua maioria, têm apenas graduação de nível superior e atuam na educação básica; 3) a intenção de aglutinar vários autores num mesmo projeto. (CENTENO, 2010, p. 24).

As deduções da pesquisadora explicitam sua angústia ao deparar-se com uma obra que omite os autores e indica uma equipe editorial com formação acadêmica menor (CENTENO, 2010). De nossa parte, não poderíamos considerar que esta concentração de elaboradores da coleção na educação básica possa mostrar-se como uma forma de aproximação entre a obra e seus possíveis compradores?

Falamos anteriormente que a autoria coletiva é uma característica das obras organizadas pelo grupo Santillana. A informação encontra-se na capa da primeira edição de 2006, feita para o PNLD de 2008: “Organizadora: Editora Moderna. Obra coletiva concebida, desenvolvida e produzida pela editora Moderna”. Dentre todas as obras aprovadas pelo PNLD daquele ano, ela foi a única com referência a uma autoria coletiva.

Esta característica deve ser analisada com certa cautela. Como dissemos no item anterior, do ponto de vista mercadológico, existem alguns benefícios para a editora já que um livro sem autoria é um livro que não paga direitos autorais e não exige gastos com viagens de divulgação do autor. Além disso, a existência de uma equipe editorial com professores atuantes na educação básica é outro atrativo que não podemos ignorar, uma vez que torna a obra mais próxima dos professores que irão ou não selecioná-la.

Sob o ponto de vista dos conteúdos, métodos e teorias utilizados na constituição, uma obra coletiva pode ser considerada eclética, mas, neste caso, pressupomos que todos os profissionais envolvidos na sua produção tinham o conhecimento necessário para desenvolver um livro didático com esta configuração.

Sob o ponto de vista conceitual, Chartier (1998, p. 32, grifos do autor) afirma que para existir o autor, “[...] são necessários critérios, noções, conceitos particulares. O inglês 
evidencia bem esta noção e distingue writer, aquele que escreveu alguma coisa, e o author, aquele cujo nome próprio dá identidade à autoridade do texto”. A autoria coletiva, estampada na capa da coleção, funciona como uma autoria no sentido de atribuir identidade à obra. Esta ênfase ocorre apenas nas edições para o PNLD e não nas de escolas particulares. Isto se deve à obrigatoriedade de indicação da autoria, expressa no edital de convocação para inscrição de coleções didáticas (BRASIL, 2005).

Dissemos que a coleção Projeto Araribá - História apresenta equipes editoriais diferentes conforme a edição - mobilidade ligada ao fato de não haver um autor - e no caso da edição que analisamos nesta pesquisa, existe uma equipe de seis profissionais diretamente envolvidos na elaboração dos originais. Dentre eles, o profissional com maior titulação tinha, na época, formação em História e mestrado em História Social do Trabalho, um tinha formação em História e mestrado em Ciências da Comunicação, dois eram graduados em História com formação recente - inclusive a editora responsável -, um era formado em Educação Física e Jornalismo com mestrado em Filosofia e o último era formado em Administração com mestrado em História Econômica. Essa diversidade possivelmente contribuiu para a constituição da concepção teórica, dos conteúdos e da metodologia de ensino. Entretanto, essa afirmação torna-se frágil por dois motivos: primeiramente, porque a obra vinha sendo editada desde 2003 e, portanto, não podemos saber até que ponto uma afirmação é de autoria de um ou de outro responsável pelos originais, seja ele da edição que analisamos ou de qualquer uma das anteriores; segundo, existem outros profissionais envolvidos com a elaboração da coleção que não são mencionados na edição do PNLD de 2008 e outros nunca foram em nenhuma das edições existentes ${ }^{19}$.

\section{Considerações finais}

Por meio desta análise, procuramos sistematizar alguns dos indícios que ajudam a entender a criação da obra Projeto Araribá - História e os fatores que levaram ao sucesso da coleção. Neste sentido, abordamos, de maneira crítica, os aspectos que envolveram sua

\footnotetext{
${ }^{19}$ As falas de Maria Raquel Apolinário possibilitam termos a dimensão da complexa constituição da obra ao afirmar que ela "[...] se iniciou com avaliações de vários livros didáticos de história para esse segmento no Brasil e com a leitura de vários documentos que nos ajudariam a desenhar o projeto [...]. Depois disso, sob a orientação do espanhol Jaime Mascaró, começamos a elaborar a unidade modelo. Ela ficou pronta, a submetemos à avaliação de professores em vários focus group promovidos pela empresa e, com base nesse feedback, fizemos reajustes para chegar à estrutura definitiva. Começamos então a elaborar os originais, tarefa que ficou por conta da equipe de editores com a colaboração fundamental de professores da História da USP, da PUC (hoje, há colaboradores de universidades de Minas, Rio de Janeiro e Bahia) e de escolas públicas e privadas de São Paulo" (APOLINÁRIO, 2011). Nem todos os colaboradores são mencionados na coleção.
} 
constituição, mas também, os que se relacionaram à sua divulgação e ao sucesso obtido no PNLD de 2008.

Buscando evitar determinismos unidirecionais, acreditamos que, para discutirmos esse sucesso, é indispensável uma análise que consiga compreender a complexidade do objeto. Se ele pode, de certa forma, ser considerado uma ferramenta para o desenvolvimento das habilidades de leitura proficientes - demanda que se intensifica no início do século XXI -, essa constatação não se atrela a maniqueísmos, mas dialoga com outros aspectos: uma boa avaliação obtida no PNLD, as estratégias de venda agressivas e a autoria coletiva contribuem para a compreensão dessa complexa rede de relações que, de modo geral, torna explícita a história recente dos livros didáticos.

Precisamos lembrar que estas etapas são compostas de sujeitos inseridos em um tempo e lugar onde as escolhas têm enormes consequências. Inquestionavelmente, para as editoras, o lucro é o principal objetivo e o mercado de livros didáticos no Brasil proporciona isso. Mesmo que o preço final seja menor em relação aos livros utilizados por escolas particulares, o PNLD tem grande importância para as editoras que enveredam por esse caminho.

A avaliação do PNLD tem um papel fundamental. Para as escolas públicas, ela funciona como parâmetro pelo fato de selecionar as coleções aptas ou não, segundo critérios aprimorados ao longo de suas edições. Mesmo que, em certos casos, o guia não seja lido durante o processo de escolha, ele está lá e interfere, mesmo que essa influência seja mínima.

Embora fosse pertinente adentrarmos no processo de avaliação da coleção analisada, apresentar essa análise exigiria a escrita de outro artigo. A discussão do ponto de vista mercadológico, presente neste texto, é um fragmento de nossa dissertação na qual apresentamos outros focos de análise dessa obra. Ressaltamos que o livro didático, entendido como objeto cultural complexo, deve ser analisado de maneiras diversas e, neste artigo, nos propusemos a apresentar apenas uma das possibilidades.

Considerando esta análise, um dos aspectos mais importantes é a intensidade e o foco das estratégias de venda da coleção Projeto Araribá - História. Sabemos que a preocupação com o desenvolvimento das habilidades de leitura não é recente. Mas percebemos que as cobranças pelo seu desenvolvimento intensificam-se em épocas de divulgação dos resultados do IDEB. Quando o índice cai, todos buscam responsáveis. A mídia, o Estado, as famílias, os professores, mas, geralmente, os últimos costumam ser os mais responsabilizados. Assim, buscar uma ferramenta que ajude no desenvolvimento da leitura proficiente acaba sendo uma das alternativas para reverter o quadro. As coleções que se propõem a isso, de maneira explícita, têm larga vantagem. Principalmente se uma de suas características for a linguagem 
simples atrelada ao desenvolvimento de habilidades específicas, como é o caso da coleção analisada neste artigo.

Acreditamos, portanto, que o sucesso da coleção está ligado às relações entre a editora, o governo e os seus compradores finais; relações estas que tornam evidentes: uma real necessidade de desenvolvimento da leitura proficiente; uma coleção que se apresenta como possibilidade de resolver tais problemas, e; por fim, uma avaliação que legitima a proposta defendida pela coleção.

Existem alguns perigos, no meio dessas complexas relações, que nos levam a problematizar toda essa situação vivida nos dias de hoje. Primeiramente, ao ressaltarmos os discursos que insistem em diminuir a importância do livro didático em sala de aula, inculcando, nos educadores, que a utilização de outros recursos, principalmente os midiáticos, é uma evolução em relação aos livros estáticos, limitados e desinteressantes, corremos o risco de selecionar aquele material que, a primeira vista, seja minimamente adequado. Denegrir esse objeto, em favor de qualquer outra metodologia, é uma atitude politicamente perigosa porque as seleções do PNLD sempre acontecerão, o livro didático continuará a ser um material universal e as editoras lucrarão com todo esse processo.

Segundo, a busca pela simplicidade tem sido uma opção recorrente de alguns livros didáticos. Ser muito simples não significa, necessariamente, que o conhecimento histórico seja adequadamente trabalhado. Além disso, a linha entre um conteúdo minimamente abordado e o conhecimento instrumentalizado é muito tênue, principalmente quando as preocupações educacionais estão direcionadas para as habilidades de leitura. Devemos nos preocupar com isso em História, mas não podemos esquecer que desenvolver um olhar crítico em relação à sociedade também é uma prioridade. Os livros didáticos têm um papel importante neste sentido.

Assim, escolher e utilizar o livro didático em sala são atitudes muito importantes. Se quisermos, efetivamente, melhorar a qualidade do ensino, escolher um bom material é fundamental. Sermos atentos quanto às propagandas, cuidadosos nas análises e criteriosos nas seleções pode ser a diferença entre fazermos uma boa escolha ou acreditarmos que isso não faz diferença e, portanto, qualquer escolha é válida.

\section{Referências}

ABRALE; ABRELIVROS. Para formar um país de leitores: contribuições para a política do livro escolar no Brasil. 2002. Disponível em: <http://www.abrale.com.br/wpcontent/uploads/Para_formar_um_pais_de_leitores.doc>. Acesso em: 26 ago. 2012. 
APOLINÁRIO, Maria Raquel. Entrevista [mensagem pessoal]. Mensagem recebida por <b_crowesbr@hotmail.com>em 19 dez. 2011.

BATISTA, Antonio Augusto Gomes. Recomendações para uma política pública de livros didáticos. Brasília: MEC/SEF, 2001.

BITTENCOURT, Circe. Ensino de História: fundamentos e métodos. São Paulo: Cortez, 2005.

Livro didático e saber escolar (1810-1910). São Paulo: Autêntica, 2008.

BRASIL. SAEB 2001: relatório Saeb 2001 - língua portuguesa. Brasília: INEP, 2001a.

PISA 2000: relatório nacional. Brasília: INEP, 2001b.

Edital de convocação para inscrição no processo de avaliação e seleção de obras didáticas a serem incluídas no guia de livros didáticos para os anos finais do ensino fundamental - PNLD 2008, de 29 de dezembro de 2005. Programa nacional do livro didático - PNLD 2008, Poder Executivo, Brasília, DF, 29 dez. 2005.

Guia de livros didáticos PNLD 2008: História. Brasília: MEC, 2007.

Portaria normativa $\mathrm{n}^{0} 7$, de 5 de Abril de 2007. Gabinete do ministro, Poder Executivo, Brasília, DF, 5 abr. 2007.

CAFARDO, Renata. Novo livro didático é questionado. O Estado de São Paulo, São Paulo, 03 out. 2007a. Disponível em: <http://www.abrelivros.org.br/index.php?option=com_content \&view=article\&id=2055:novo-livro-didatico-e-questionado\&catid=1:noticias\&Itemid=2>. Acesso em 26 ago. 2012.

Editora admite erro em livro didático, mas nega propaganda. O Estado de São Paulo, São Paulo, 04 out. 2007b. Disponível em: <http://www.abrelivros.org.br/index.php?option= com_content\&view=article\&id=2054:editora-admite-erro-em-livro-didatico-mas-negapropaganda\&catid=1:noticias\&Itemid=2> . Acesso em 26 ago. 2012.

CASSIANO, Célia Cristina de Figueiredo. O mercado do livro didático no Brasil: da criação do Programa Nacional do Livro Didático (PNLD) à entrada do capital internacional espanhol (1985-2007). 2007. 252 f. Tese (Doutorado em Educação) - Pontifícia Universidade Católica de São Paulo, São Paulo, 2007.

CENTENO, Carla Villamaina. O manual Projeto Araribá História no município de Campo Grande, MS (2008). Revista HISTEDBR, Campinas, n. especial, p. 20-35, mai. 2010.

CHARTIER, Roger. A aventura do livro do leitor ao navegador. Tradução de Reginaldo Carmello Corrêa de Moraes. São Paulo: Editora Unesp, 1998.

CHOPPIN, Alain. Traiter le manuel scolaire comme source documentaire: une approche historique. Revista língua escrita, Belo Horizonte, n.3, p. 1-10, dez. 2007. 
COELHO, Araci Rodrigues. Usos do livro didático de História: entre prescrições e táticas. 2009. 438 f. Tese (Doutorado em Educação) - Universidade Federal de Minas Gerais, Belo Horizonte, 2009.

FREITAS, Itamar; SANTOS, Aldeni Pinheiro; MENEZES, André Amaral; SILVA, Elineide dos Santos; SANTOS, Elisângela de Jesus. A ação do PNLD em Sergipe e a escolha do Livro Didático de História (2005/2007): exame preliminar. In: OLIVEIRA, Margarida Maria Dias de; STAMATTO, Maria Inês Sucupira (Orgs.). O livro didático de História: políticas educacionais, pesquisas e ensino. Natal: EDUFRN, 2007. p. 53-59.

GATTI JÚNIOR, Décio. A escrita escolar da História: livro didático e ensino no Brasil (1970-1990). Bauru: EDUSC; Uberlândia: EDUFU, 2004.

INSTITUTO PRÓ-LIVRO. Retratos da leitura no Brasil. 2008. Disponível em: < http://pt.scribd.com/doc/27340728/Retratos-Da-Leitura-No-Brasil>. Acesso em: 26 ago. 2012.

JORNAL EDUCAR. Rio de Janeiro: Appai. n. 56, 2008.

KOIKE, Beth. Dono das editoras Moderna, Objetiva e Salamandra não descarta novas aquisições. Valor Econômico, São Paulo, 27 mai. 2009. Disponível em:

$<$ http://www.abrelivros.org.br/index.php?option=com_content\&view=article\&id=2507:donodas-editoras-moderna-objetiva-e-salamandra-nao-descarta-novas-aquisicoes\&catid=1:noticias \&Itemid=2>. Acesso em: 26 ago. 2012.

LIVROFACIL. História em Projetos: $6^{\circ}$ ano $/ 5^{\text {a }}$ série. Disponível em: < http://www.livrofacil.com/index.php/historia-em-projetos-6-ano-5-serie.html>. Acesso em: 26 ago. 2012.

MACHADO, Nilson José. Sobre livros didáticos-, quatro pontos. Em Aberto, Brasília, a. 16, n. 69, p. 30-38, jan./mar. 1996.

MIRANDA, Sonia Regina; LUCA, Tânia Regina de. O livro didático de história hoje: um panorama a partir do PNLD. Revista brasileira de História, São Paulo, v. 24, n. 48, p. 123144, 2004.

MUNAKATA, Kazumi. Produzindo livros didáticos e paradidáticos. 1997. 223 f. Tese (Doutorado em História e Filosofia da Educação) - Pontifícia Universidade Católica de São Paulo, São Paulo, 1997.

O livro didático e o professor: entre a ortodoxia e a apropriação. In: MONTEIRO, Ana Maria; GASPARELLO, Arlette Medeiros; MAGALHÃES, Marcelo de Souza (Orgs.). Ensino de história: sujeitos, saberes e práticas. Rio de Janeiro: Mauad; FAPERJ, 2007. p. 137-147.

OCDE. Conhecimentos e atitudes para a vida: resultados do PISA 2000. São Paulo: Moderna, 2003. 
PINHO, Angela; SELIGMAN, Felipe. Compras do MEC fazem anônimo virar best seller. Folha Online, Brasília, 20 set. 2007. Disponível em <http://www1.folha.uol.com.br/folha/ educacao/ult305u332592.shtml>. Acesso em 26 ago. 2012.

PROJETO ARARIBÁ. História 7: ensino fundamental. 1. ed. São Paulo: Moderna, 2003. História $7^{a}$ série. 1. ed. PNLD-2008. São Paulo: Moderna, 2006.

Site de divulgação da coleção. Disponível em: <http://www.moderna.com.br/ arariba/>. Acesso em: 25 ago. 2012.

SILVA, Marco Antonio. A formação leitora no livro didático de História. 2009. 229 f. Dissertação (Mestrado em Educação) - Universidade Federal de Minas Gerais, Belo Horizonte, 2009.

TIMBÓ, Isaíde Bandeira. O livro didático de História: um caleidoscópio de escolhas e usos no cotidiano escolar (Ceará, 2007 - 2009). 2009. 273 f. Tese (Doutorado em Educação) Universidade Federal do Rio Grande do Norte, Natal, 2009. 